\title{
Desarrollo e implementación de un modelo de características o indicadores de calidad para evaluar los blogs de bibliotecas escolares de centros de educación infantil y primaria
}

\author{
José Enrique García-Romero*, Cristina Faba-Pérez* \\ *Departamento de Información y Comunicación, Facultad de Ciencias de la Documentación y la Comunicación, \\ Universidad de Extremadura, Badajoz, España \\ Correo-e: josegarciaromero@hotmail.com, cfabper@unex.es
}

Recibido: 13-03-2014; 2a versión: 09-05-2014; Aceptado: 14-05-2014.

Cómo citar este artículo/Citation: García-Romero, J. E.; Faba-Pérez, C. (2015). Desarrollo e implementación de un modelo de características o indicadores de calidad para evaluar los blogs de bibliotecas escolares de centros de educación infantil y primaria. Revista Española de Documentación Científica, 38(1): e078. doi: http://dx.doi.org/10.3989/redc.2015.1.1169

Resumen: El objetivo del presente trabajo es el desarrollo de un modelo ponderado de características o indicadores de calidad para la evaluación específica de los blogs de bibliotecas escolares para centros de educación infantil y primaria, así como su aplicación práctica en la población concreta de los centros públicos de la Comunidad de Extremadura en España, con el fin de obtener un ranking de los mismos basado en las características que incluyen. El desarrollo del modelo, que comienza con el diseño previo de una plantilla de 32 características, se centra en dos parámetros: el peso específico asignado a cada característica por dos grupos de expertos según su nivel de importancia para los blogs (elegido entre los valores 1,2 y 3 ); y el grado de cumplimiento de cada una de ellas en cada blog analizado (valores $0,0,5$ o 1 ). Los resultados de la aplicación práctica del modelo demuestran que hay una elevada proporción de características $(65,62 \%)$ que no son cumplidas en ninguna medida por más del $50 \%$ de los blogs y que el número de habitantes de la localidad extremeña a la que pertenecen los centros escolares cuyos blogs se analizan y, por consiguiente, los recursos humanos y tecnológicos disponibles para su desarrollo, no influyen directamente en la posición que éstos obtienen en un ranking de calidad basado en sus características.

Palabras clave: Modelo de indicadores de calidad; blog; biblioteca escolar; educación infantil y primaria; Comunidad de Extremadura (España).

Design and Implementation of a Features or Indicators Model for Evaluating School Library Blogs in Preschool and Primary Education Centers

Abstract: The purpose of the present work was to design a weighted features or indicators model for the specific evaluation of school library blogs for preschool and primary education, and to apply it to public education centers in Extremadura (Spain), resulting in a quality ranking of the blogs based on the features included. The design of the weighted features model started with the prior design of 32 indicators. The model is based on two parameters: the weight assigned to each feature by two expert groups according to its relevance for blogs (values of 1,2 and 3), and the blogs' degree of compliance with that feature (values of $0,0.5$ or 1 ). The results of this practical application of the model show that a high proportion of features $(65.62 \%)$ are not included by more than $50 \%$ of the blogs, and factors such as the number of inhabitants in a blog's geographical region do not directly influence its quality ranking.

Keywords: Quality Indicators Model; blog; school library; preschools and primary education; Region of Extremadura (Spain).

Copyright: (c) 2015 CSIC. Este es un artículo de acceso abierto distribuido bajo los términos de la licencia Creative Commons Attribution-Non Commercial (by-nc) Spain 3.0. 


\section{INTRODUCCIÓN}

Los cambios vertiginosos que se han producido en los últimos años en las Tecnologías de la Información y Comunicación (TIC) y, en concreto en la Web, han llegado también a las bibliotecas escolares, puesto que la conexión de la escuela al Ciberespacio como método didáctico es fundamental para el aprendizaje colaborativo (Marzal y otros, 2011). De las actuales tecnologías en línea, el diseño y el uso de los blogs ha tenido gran implantación en este tipo de bibliotecas, ya que promueven espacios de diálogo, creación y aprendizaje (Moreno Mulas, 2006; Rodríguez-Palchevic, 2010), por lo que se han convertido en una herramienta fundamental para el desarrollo de las competencias informacionales básicas imprescindibles en la educación (Blasco Olivares y Durban Roca, 2012), siendo de una gran importancia para integrar las TIC en los aprendizajes elementales de los alumnos. La relación de las TIC y las bibliotecas escolares ha sido un aspecto ampliamente reiterado en normativas internacionales (Directrices de la IFLA/UNESCO para la Biblioteca Escolar, 2002; Manifiesto de la IFLA/UNESCO sobre internet, 2006), nacionales (Ley Orgánica de Educación LOE, 2006; Ley Orgánica para la Mejora de la Calidad Educativa LOMCE, 2013) y regionales (Plan Marco de Apoyo y Fomento de las Bibliotecas Escolares de Extremadura ${ }^{1}$, 2006; Orden de 25 de abril de 2007 por la que se promueve la Red de Bibliotecas Escolares de Extremadura, 2007; Orden de 5 de junio de 2012 por la que se modifica la Orden de 25 de abril de 2007, 2012; Ley de Educación de Extremadura, 2011).

Con respecto a los blogs, actualmente nos encontramos ante una realidad en la Web que tiene tres sinónimos: weblog (compuesta por los términos web y log -registro-) para los puristas apasionados de nuevos términos tecnológicos, blog para los que optan por la economía del lenguaje y por último, bitácora para los que se resisten a emplear extranjerismos teniendo la oportunidad de utilizar una palabra castellana. Aunque existe una revisión exhaustiva sobre definiciones de blogs realizada por Noguera Vivo (2008), en la $1^{\text {a }}$ edición del Diccionario Panhispánico de Dudas de la Real Academia Española (2005, http://lema.rae.es/dpd/?key=weblog) se recoge una acepción exacta de blog o weblog, remitiendo al español bitácora y que define concretamente como "sitio electrónico personal, actualizado con mucha frecuencia, donde alguien escribe a modo de diario o sobre temas que despiertan su interés, y donde quedan recopilados asimismo los comentarios que esos textos suscitan en sus lectores". La frescura del estilo de escritura (Orihuela, 2003), el trabajo colaborativo (Balslev y Winther, 2004) y su carácter como herramienta de diálogo y comunicación horizontal (Noguera Vivo, 2004) y como medio de auto-comunicación de masas que posibilita el poder seleccionar, modificar y combinar lo que se recibe y se envía (Castells, 2009) son algunas de las características más identificativas de los blogs.
La implementación de los blogs en las bibliotecas escolares ha sido rápida, principalmente debido a que es una herramienta económica y fácil de utilizar, al mismo tiempo que permite la interacción entre el creador y los usuarios. Margaix Arnal (2008) citando a Juárez Urquijo (2008) indica que "los blogs han supuesto en las bibliotecas un ejemplo de cómo la tecnología está al alcance de (casi) todas las bibliotecas y la innovación en la prestación de los servicios ya no va a estar en manos de aquellos que tienen grandes presupuestos, estará en manos de aquéllos que tengan suficiente imaginación y pocas barreras para poner en marcha sus ideas". Algunas de las aplicaciones más frecuentes de los blogs en las bibliotecas escolares han sido recogidas por Farkas (2007): blogs de noticias, blogs de clubes y recomendación de lectura, blogs de marketing y blogs para construir comunidad. En general, los blogs de bibliotecas escolares son una mezcla de todos ellos y no tienen un solo perfil definido.

Siguiendo a Rodríguez-Palchevich (2010), consideramos que una biblioteca escolar puede desarrollar y mantener un blog competente para las necesidades de su comunidad educativa siempre que el centro escolar tenga acceso a internet de alta velocidad, hardware y software actualizado y profesionales de la información con vocación y formación en el uso de las nuevas tecnologías. En la actualidad, prácticamente todos los centros educativos de la Comunidad Autónoma de Extremadura disponen de un acceso a internet con la suficiente velocidad como para poder crear su propio blog educativo. Sin embargo, no existe ninguna investigación que permita conocer el estado de los blogs de las bibliotecas escolares en Extremadura, ni se han desarrollado prácticamente modelos detallados que permitan evaluar específicamente las características de este tipo de webs. Estas características forman parte de un conjunto de indicadores conocidos como indicadores webométricos de características, que se enmarcan en la disciplina denominada Webometrics que "consiste en un análisis cuantitativo de los fenómenos de la Web, incluyendo el análisis de enlaces y el análisis descriptivo o de características de la Web" (Al-Duwairi y otros, 2010). La evaluación mediante modelos de análisis de características se fundamenta en el hecho de que los sitios web por más disímiles que sean, tienen unas características comunes o indicadores de calidad que permiten su valoración y equiparación.

Por ello, el objetivo del presente trabajo es el diseño o desarrollo de un modelo ponderado de características o indicadores de calidad para la evaluación específica de los blogs de bibliotecas escolares para centros de educación infantil y primaria, así como su aplicación práctica en la población concreta de blogs de bibliotecas escolares de centros públicos de educación infantil y 
primaria y colegios rurales agrupados de la Comunidad de Extremadura, con el fin de obtener un ranking de los mismos basado en las características que incluyen. Este trabajo parte de la hipótesis de que es posible diseñar un modelo de características ponderadas para este tipo de blogs contando con la cooperación de expertos para obtener unos resultados objetivos sobre la situación de los blogs analizados. Así mismo, se cuestiona si el número de habitantes de la localidad extremeña a la que pertenecen los centros escolares cuyos blogs se analizan y, por consiguiente, los recursos humanos y tecnológicos disponibles para su desarrollo, podría influir en la posición que éstos obtengan en la clasificación final atendiendo a sus características web.

\section{MATERIAL Y METODOLOGÍA}

\subsection{Material}

Los centros educativos de enseñanzas no universitarias que pueden tener blogs de bibliotecas escolares se pueden dividir en dos grandes grupos: centros de infantil y primaria (abarca los centros de educación infantil, primaria y colegios rurales agrupados) y centros de secundaria (agrupa los centros de secundaria, formación profesional y escuelas de idiomas). Las características de los centros y la formación técnica de los administradores de los blogs difieren mucho en ambos casos, por lo que comparar y analizar blogs de bibliotecas escolares de los dos grupos debe hacerse por separado.

La aplicación práctica del modelo ponderado de características diseñado en la presente investigación y detallado seguidamente en la Metodología se realiza con los blogs de bibliotecas escolares pertenecientes a los centros públicos de educación infantil y primaria porque reúnen las mismas particularidades de cara al análisis: en primer lugar, los alumnos tienen entre tres y doce años y poseen unas características propias que los diferencian claramente del alumnado de secundaria (no hacen uso de las TIC de forma similar a los de secundaria ya que, en general, su acceso a las redes sociales es muy limitado y tienen un amplio control familiar en sus accesos a la Web); en segundo lugar, el profesorado que compone estos centros está formado única y exclusivamente por maestros/as de las distintas especialidades cuya formación académica de acceso a la docencia es similar en todos los casos.

En secundaria, sin embargo, la plantilla docente está formada por un amplio abanico de profesorado de múltiples disciplinas, entre los que se encuentran informáticos, que colaboran activamente en la creación, gestión y administración de los blogs de bibliotecas escolares de estos centros. El hecho de que el $90 \%$ de los centros concertados (54 de 60 ) y el $100 \%$ de los centros exclusivamente privados (6 de 6 ) de educación infantil y primaria de la Comunidad de Extremadura sean también centros de secundaria $y$, por consiguiente, tengan sus mismas características hace que se descarten para el presente estudio. Con respecto al $10 \%$ de los centros concertados que imparten únicamente educación infantil y primaria no disponen de blog de su biblioteca escolar.

Para recopilar la población objeto de estudio, en primer lugar, se consulta el censo oficial de los centros de educación infantil y primaria (CEIP), así como centros rurales agrupados (CRA) del curso 2012-2013 de la Comunidad de Extremadura publicado por la Consejería de Educación y Cultura (http://v2.educarex.es/ web/guest/listado-centros) que asciende a 414 centros distribuidos de la siguiente forma: 374 CEIP ( 228 en Badajoz -60,96\%- y 146 en Cáceres $-39,04 \%$ ) y 40 CRA ( 14 en Badajoz -35\%-y 26 en Cáceres -65\%).

En segundo lugar, se comprueba si cada uno de los 414 centros hace referencia a la web de su biblioteca escolar y, si ésta dispone o no de blog. Por último, se obtiene la población final de estudio formada por un conjunto de 75 blogs de bibliotecas escolares de centros públicos de la Comunidad de Extremadura (18,11\% del total) con la siguiente distribución: 67 blogs de CEIP (39 en Badajoz -58,2\%- y 28 en Cáceres -41,8\%) y 8 blogs de CRA ( 1 en Badajoz $-12,5 \%$ - y 7 en Cáceres $-87,5 \%)$.

\subsection{Metodología}

Para diseñar el modelo ponderado de características o indicadores de calidad que permita la evaluación concreta de los blogs de bibliotecas escolares, previamente se ha ideado una plantilla específica de características. Para ello, en primer lugar, se consultan modelos propuestos por distintos autores relacionados, tanto con el análisis de características para sitios web en general (García de León y Garrido Díaz, 2002; Ayuso García y Martínez Navarro, 2006a; Calderón Rehecho, 2006), como para webs de unidades informativas (Ayuso García y Martínez Navarro, 2006b; Robert Barrera y otros, 2006; Consejo de Cooperación Bibliotecaria, 2007; Faba-Pérez y Sanz-Caballero, 2014) y de bibliotecas escolares en particular (Clyde, 2004; Luque Jaime, 2007; González-Mateos y Faba-Pérez, 2014) y, en concreto, para blogs de bibliotecas escolares (Luque Jaime, 2011). Estos últimos prácticamente inexistentes. En segundo lugar, para proceder a una selección de criterios ajustada a la población de estudio, se realiza la observación directa de los 7 blogs ganadores y 15 finalistas de los VI (2012) y VII (2013) Premios Espiral de Edublogs (http://espiraledublogs.org) en la categoría de Bibliotecas Escolares. 
Aunando ambos métodos se genera una primera plantilla formada por 50 características clasificadas en siete apartados (Información General, Contenidos, Enlaces, Servicios, Programas y actividades, Publicaciones, Herramientas sociales y de participación en línea) que se contrastan con un conjunto de expertos (informáticos y maestros/as) con el fin de depurarla y seleccionar solo las más pertinentes para este trabajo en cuestión enfocado a blogs de bibliotecas escolares. Dicho conjunto de expertos también es requerido en la siguiente fase del modelo, donde se especifica con más detalle.

Tras el estudio de los trabajos empíricos mencionados, la observación directa de blogs por parte de los analistas y la consulta a expertos, se genera una plantilla definitiva formada por 32 características clasificadas en cuatro apartados (Información General, Contenidos, Enlaces y Servicios).

Una vez ideada la plantilla, se diseña un modelo ponderado de características o indicadores teniendo en cuenta dos parámetros: el peso específico asignado a cada característica según su nivel de importancia para los blogs de bibliotecas escolares, y el grado de cumplimiento de cada una de ellas en cada blog analizado.

Con respecto al primer parámetro del modelo, se cuenta con la colaboración de un grupo de 22 expertos: 12 informáticos que trabajan en centros públicos de educación secundaria o en la administración educativa en temas relacionados con las bibliotecas escolares y/o el diseño web y 10 maestros/as que pertenecen a los equipos de bibliotecas de sus centros. Dichos expertos proponen un peso para cada característica eligiendo entre los valores 1,2 y 3 . El peso final para cada característica se obtiene con la media aritmética de sus valoraciones. Del análisis de las medias de las valoraciones asignadas por el grupo de informáticos y de maestros/as, se obtiene una correlación positiva sustancial de $r=0,6$ lo que significa que las ponderaciones asignadas por ambos colectivos, en general, van acompasadas.

Para el segundo parámetro del modelo se proponen los valores $0,0,5$ y 1 para determinar el grado de cumplimiento de cada característica en cada blog. En general, se califica con un 0 cuando el grado de cumplimiento de la característica en el blog es deficiente, con 0,5 cuando es suficiente y con 1 cuando destaca notablemente.

La recopilación de los datos para el análisis de los blogs se realiza en el menor tiempo posible y durante el periodo estival (del 20 de julio al 10 de septiembre de 2013) con la finalidad de ser lo más objetivo y equitativo posible en la recogida de datos, ya que durante dicho periodo los centros educativos permanece cerrados $y$, por consiguiente, los blogs de sus bibliotecas escolares se mantienen más estáticos.
El Anexo I muestra detalladamente el modelo ponderado de características o indicadores diseñado en esta investigación para la evaluación de blogs de bibliotecas escolares. En él aparece el código de cada característica, su nombre y descripción, el primer parámetro del modelo (peso asignado a cada característica según la media de los expertos entre 1 y 3) y el segundo parámetro del modelo (grado exacto de cumplimiento de cada característica en cada blog $0,0,5 \circ 1$ ).

\section{RESULTADOS}

\subsection{Evaluación de las características en los blogs analizados}

El análisis individualizado de los resultados de cada una de las 32 características o indicadores que forman parte del modelo teniendo en cuenta en qué grado se cumple cada una de ellas $(0,0,5$, 1) en los 75 blogs de bibliotecas escolares estudiados, se muestra en la Tabla I. Si se analizan las características asociadas a más del $50 \%$ de los blogs, se observa que 21 de ellas $(65,62 \%)$ tienen un grado de cumplimiento G.C. 0 , solo 2 características tienen un G.C. 0,5 (6,25\%) y 6 de ellas son cumplidas en su máximo grado G.C. 1 por más del $50 \%$ de los blogs, lo que supone un escaso $18,75 \%$.

Si se analizan con detalle los valores extremos de las características asociadas a más del $80 \%$ de los blogs, se observa que C10, C16, C25, C27, C28 y C32 son las menos favorecidas, mientras que C8, C12 y C26 se sitúan a la cabeza como las características mejor cumplidas por más del $80 \%$ de los blogs analizados. La explicación de tales resultados va asociada a la idiosincrasia particular de cada característica y a la población objeto de estudio:

- C10. La edad de los alumnos (tres-doce años) es fundamental a la hora de decidir la implementación de las herramientas sociales en los blogs. Teniendo en cuenta, por un lado, que los alumnos de infantil y primaria no suelen hacer un uso importante de estas herramientas sociales (más enfocadas a los padres y al profesorado) y, por otro, los problemas que existen en la gestión y administración del blog, parece lógico que la incorporación de herramientas sociales en los blogs no se estime rentable, dado el esfuerzo añadido que supone su gestión y el poco uso de las mismas por parte del principal público al que va dirigido el blog: el alumnado.

- C16. La traducción del blog a otros idiomas está muy poco implementada. Sin embargo, sería muy interesante para unos centros educativos que, en muchos casos, son fronterizos con Portugal, país con el que se mantienen numerosos contactos e intercambios. Además, muchos centros están inmersos en las políticas de implantación del bilingüismo y del tercer idioma. 
- C25. Para realizar y gestionar recomendaciones de lectura efectuadas por alumnos se requieren unos conocimientos básicos y un tiempo del que normalmente no se dispone en los centros de educación infantil y primaria, ya que la administración y gestión del blog suele estar en manos de una sola persona, lo cual dificulta este tipo de tareas que son laboriosas y requieren trabajos adicionales como escanear, conversión de archivos, editar videos, etc.

- C27 y C28. El análisis de estas dos características se realiza de manera conjunta debido a su íntima relación. No hay ningún blog que tenga recogida la posibilidad de efectuar préstamos y solo uno facilita el acceso a su catálogo de manera on-line. La primera versión operativa del programa AbiesWeb, desarrollado por el Ministerio de Educación y que se está distribuyendo a las Comunidades participantes en el proyecto ofrece la posibilidad de acceso al catálogo online pero no posibilita el préstamo on-line, por lo que podrá favorecer la incorporación del catálogo en los blogs de las bibliotecas escolares, pero no del préstamo.

- C32. En este nivel educativo muy pocos centros disponen de clubes de lectura. Este puede ser el motivo de que muy pocos blogs informen de los clubes de lectura de sus centros escolares y, menos aún, de su programación y actividades.

Entre las características o indicadores que han obtenido mejor valoración se encuentran:

- C8. En la mayoría de los blogs los títulos de las entradas son significativos y describen adecuadamente el contenido de los mismos, cumpliendo con la función que tienen asignada.

- C12. En la mayoría de los blogs de bibliotecas escolares, los textos e imágenes que se utilizan son producciones propias, por lo que los derechos de autor le pertenecen a ellos. Por este motivo, cuando utilizan imágenes o textos se citan adecuadamente los autores y se indica la fuente de los mismos.

- C26. De los datos se desprende que en la mayoría de los blog analizados los enlaces que se encuentran en la página principal del blog son de fuentes fiables y relevantes.

\subsection{Ranking de los blogs analizados}

En este caso se aplica el modelo completo diseñado para obtener la clasificación de los blogs de las bibliotecas escolares de Extremadura, es decir, la plantilla de características o indicadores de calidad, el grado de cumplimiento y el peso de cada una de ellas según la valoración de los expertos. De este modo, obtenemos la puntuación final de cada blog que aparece en el Anexo II y responde a la fórmula siguiente que forma parte de un estudio anterior de Faba-Pérez y otros (2005):

$$
S_{p}=\sum_{i=1}^{n} p_{i} x_{i}
$$

donde:

$S_{p}$ es la suma ponderada de las características de cada blog:

$p_{i}$ es el peso asignado a cada característica i-ésima

$x_{i}$ es el grado de cumplimiento de cada característica i-ésima en cada blog

$n$ se corresponde con el número total de características analizadas en cada blog $=32$.

La clasificación en función de la calificación global obtenida por cada uno de los blogs analizados se refleja en el Anexo II. La media de las puntuaciones globales obtenidas por los blogs de la Comunidad de Extremadura es de 31,19. El 43\% de los blogs están por encima de la media, siendo el último valor que la supera 31,25 correspondiente al blog "Leo y te cuento" situado en la posición 32 de la clasificación.

Se ha estudiado detenidamente la posición de los blogs en el ranking obtenido, con el fin de identificar si el número de habitantes que tienen las localidades a las que pertenecen los centros de referencia de los blogs de bibliotecas escolares analizados influye en la posición alcanzada. Para este estudio, se han consultado los datos del Instituto Nacional de Estadística correspondientes al año 2012 y se han establecido dos grupos de localidades: $>10.000$ habitantes y $<10.000$. De los 75 blogs, 34 $(45,33 \%)$ se encuentran en localidades de $>10.000$ habitantes y $41(54,67 \%)$ en poblaciones $<10.000$ habitantes. Con respecto a su posición en el ranking, el $56 \%$ de los blogs que se hallan por encima de la media, es decir, que obtienen mejores resultados, se encuentran en localidades de $>10.000$ habitantes y el $63 \%$ de los blogs por debajo de la media pertenecen a localidades < 10.000 habitantes (Tabla II). Sin embargo, es significativo que blogs de centros situados en localidades de $<10.000$ habitantes ocupen algunas primeras posiciones de la clasificación. Así, en la provincia de Cáceres el segundo mejor clasificado corresponde al blog "El bosque de los libros" del CRA "Traslasierra" de las localidades de Castañar de Ibor, Rebollar y Cabezabellosa, que no alcanzan entre las tres los 2.000 habitantes, y en la provincia de Badajoz el blog que ocupa la primera posición, "Bibliotecadonalvaro" corresponde a un centro situado en una localidad, Don Álvaro, de menos de 5.000 habitantes. 
Tabla I. Grado de cumplimiento de cada característica o indicador de calidad

\begin{tabular}{|c|c|c|c|c|}
\hline & CARÁCTERÍSTICAS & G.C. 0 & G.C. 0,5 & G.C. 1 \\
\hline \multicolumn{5}{|c|}{ INFORMACIÓN GENERAL } \\
\hline $\mathbf{C 1}$ & URL del blog & $0 \%$ & $27 \%$ & $73 \%$ \\
\hline $\mathbf{C 2}$ & Definición de los objetivos del blog & $55 \%$ & $12 \%$ & $33 \%$ \\
\hline $\mathbf{C 3}$ & Identificación del organismo responsable del blog & $24 \%$ & $33 \%$ & $43 \%$ \\
\hline $\mathbf{C 4}$ & Documentos organizativos de la biblioteca escolar. (Proyectos, memorias...) & $66 \%$ & $17 \%$ & $17 \%$ \\
\hline C5 & Autoría. Personas encargadas de su mantenimiento. (Administradores) & $59 \%$ & $17 \%$ & $24 \%$ \\
\hline $\mathbf{C 6}$ & Imágenes de la biblioteca escolar. Visita virtual & $72 \%$ & $16 \%$ & $12 \%$ \\
\hline C7 & Identificación básica de las entradas & $11 \%$ & $66 \%$ & $23 \%$ \\
\hline $\mathbf{C 8}$ & Títulos de las entradas & $0 \%$ & $12 \%$ & $88 \%$ \\
\hline $\mathbf{C 9}$ & Contador de visitas & $47 \%$ & $1 \%$ & $52 \%$ \\
\hline $\mathbf{C 1 0}$ & Herramientas sociales. Pinterest, Facebook, Twitter, Youtube & $90 \%$ & $7 \%$ & $3 \%$ \\
\hline C11 & Suscripción por email y RSS & $77 \%$ & $16 \%$ & $7 \%$ \\
\hline \multicolumn{5}{|c|}{ CONTENIDOS } \\
\hline C12 & Derechos de autor & $0 \%$ & $5 \%$ & $95 \%$ \\
\hline C13 & Navegabilidad & $52 \%$ & $11 \%$ & $37 \%$ \\
\hline C14 & Herramienta de navegación interna & $1 \%$ & $72 \%$ & $27 \%$ \\
\hline $\mathbf{C 1 5}$ & Nubes de Etiquetas, Tag Cloud & $55 \%$ & $1 \%$ & $44 \%$ \\
\hline C16 & Traducción. Adaptación a la lengua del usuario & $92 \%$ & $0 \%$ & $8 \%$ \\
\hline C17 & Actualización. Frecuencia de las entradas & $59 \%$ & $5 \%$ & $36 \%$ \\
\hline \multicolumn{5}{|c|}{ ENLACES } \\
\hline C18 & Enlaces con otras bibliotecas escolares & $61 \%$ & $20 \%$ & $19 \%$ \\
\hline C19 & Enlaces a bibliotecas públicas & $71 \%$ & $10 \%$ & $19 \%$ \\
\hline $\mathbf{C 2 0}$ & Enlaces a recursos educativos relacionados con el fomento de la lectura & $43 \%$ & $24 \%$ & $33 \%$ \\
\hline $\mathbf{C 2 1}$ & Enlaces a sitios de interés: revistas de literatura infantil y juvenil, enciclopedias, etc. & $62 \%$ & $9 \%$ & $29 \%$ \\
\hline $\mathbf{C 2 2}$ & Acceso a publicaciones de carácter informativo elaboradas por la biblioteca escolar & $66 \%$ & $11 \%$ & $23 \%$ \\
\hline $\mathbf{C 2 3}$ & Acceso a la revista escolar del centro & $76 \%$ & $11 \%$ & $13 \%$ \\
\hline $\mathbf{C 2 4}$ & Promoción de materiales elaborados por los alumnos (escritos, ilustraciones) & $68 \%$ & $9 \%$ & $23 \%$ \\
\hline $\mathbf{C 2 5}$ & Recomendaciones de lecturas realizadas por alumnos & $88 \%$ & $6 \%$ & $6 \%$ \\
\hline $\mathbf{C 2 6}$ & Fiabilidad de los enlaces & $2 \%$ & $15 \%$ & $83 \%$ \\
\hline \multicolumn{5}{|c|}{ SERVICIOS } \\
\hline $\mathbf{C 2 7}$ & Préstamo & $100 \%$ & $0 \%$ & $0 \%$ \\
\hline $\mathbf{C 2 8}$ & Catálogo & $99 \%$ & $0 \%$ & $1 \%$ \\
\hline $\mathbf{C 2 9}$ & Orientación, noticias, y novedades bibliográficas & $55 \%$ & $21 \%$ & $24 \%$ \\
\hline C30 & Programas de fomento de la lectura & $26 \%$ & $25 \%$ & $49 \%$ \\
\hline C31 & Actividades y actuaciones de la biblioteca escolar & $9 \%$ & $28 \%$ & $63 \%$ \\
\hline C32 & Club de lectura & $94 \%$ & $3 \%$ & $3 \%$ \\
\hline
\end{tabular}


Tabla II. Blogs en función de las poblaciones de su centro de referencia y de la media en puntuación total

\begin{tabular}{|l|c|c|c|c|}
\hline \multirow{2}{*}{$\begin{array}{l}\text { EXTREMADURA } \\
\text { Total blogs 75 }\end{array}$} & \multicolumn{2}{|c|}{ >Media } & \multicolumn{2}{c|}{ <Media } \\
\cline { 2 - 5 } & \multicolumn{2}{|c|}{32 blogs } & \multicolumn{2}{c|}{43 blogs } \\
\hline Tipos de localidad & $>10.000$ habs. & $<10.000$ habs. & $>10.000$ habs. & $<10.000$ habs. \\
\hline Número de blogs & $18(56 \%)$ & $14(44 \%)$ & $16(37 \%)$ & $27(63 \%)$ \\
\hline
\end{tabular}

\section{CONCLUSIONES}

A continuación se exponen las conclusiones de la investigación y su relación con las hipótesis de partida:

Ante la falta de modelos concretos de características o indicadores de calidad para evaluar los blogs de bibliotecas escolares y, sin embargo, la importancia de los mismos reflejada en las numerosas Normativas sobre el uso de las TIC en la educación no universitaria, en esta investigación se ha diseñado un modelo centrado en una plantilla de 32 características específicas que se pueden considerar apropiadas porque se han obtenido mediante el estudio de trabajos empíricos, la observación de los analistas y la consulta a dos grupos de expertos muy relacionados con la materia (maestros/as e informáticos implicados en educación).

Se ha razonado detalladamente para cada una de las 32 características del modelo cómo se evalúa el grado de cumplimiento de cada una en los blogs analizados, explicando exhaustivamente la asignación de los pesos $(0,0,5 \circ 1)$.

Se ha ponderado cada característica o indicador del modelo atendiendo a la importancia de cada una de ellas para la evaluación de blogs de bibliotecas escolares. Para ello, se ha contado con la colaboración de dos grupos de expertos muy relacionados con la materia (maestros/as e informáticos implicados en educación) que han propuesto un peso para cada característica eligiendo entre los valores 1,2 y 3 . La íntima relación de los expertos con el tema tratado, así como la correlación sustancial $(r=0,6)$ hallada en las ponderaciones entre los dos grupos, apoya la elección del peso para cada característica y, por consiguiente, la objetividad de los resultados obtenidos en la evaluación de cada blog.

Para comprobar la validez del modelo se ha realizado el estudio y análisis de los blogs de bibliotecas escolares pertenecientes a centros educativos públicos (centros de educación infantil y primaria CEIP y centros rurales agrupados CRA) que imparten las enseñanzas de educación primaria de la Comunidad de Extremadura (un total de 75 blogs).

El análisis individualizado de los resultados de cada una de las 32 características que forman parte del modelo teniendo en cuenta en qué grado se cumple cada una de ellas en la población estudiada indica que, en general, hay una elevada proporción de características (el $65,62 \%$ ) que no son cumplidas en ninguna medida por más del $50 \%$ de los blogs analizados $y$, desafortunadamente, solo el $18,75 \%$ de las características son cumplidas en su máximo nivel por más del $50 \%$ de los blogs. Ello nos hace concluir que los blogs de las bibliotecas escolares de Extremadura tienen un largo camino por recorrer, por lo que trabajos de este tipo les servirán de referencia.

Con respecto a la clasificación de los blogs en la Comunidad de Extremadura según el modelo aplicado, es preciso matizar que el objetivo fundamental de este apartado es ayudar a los responsables del desarrollo de los blogs de las bibliotecas escolares en el conocimiento de la situación en la que se encuentra cada blog a tenor del modelo aplicado. Por ello, no es tan importante detallar los blogs que se hallan en las primeras o últimas posiciones de las distribuciones, sino ofrecer una visión de conjunto al respecto. No obstante, en la clasificación global de la Comunidad el blog denominado "Bibliotecadonalvaro" del CEIP Pío XII de la localidad de Don Álvaro (Badajoz) se sitúa a la cabeza de la clasificación, seguido de "El baúl de Lady Book" del CEIP Alba Plata de Cáceres capital.

Finalmente, de los 75 blogs de bibliotecas escolares analizados, el 45,33\% del total pertenecen a centros situados en localidades $>10.000$ habitantes. Con respecto a su posición en el ranking, de los 32 blogs situados por encima de la media, el 56\% se encuentran en localidades de $>10.000$ habitantes y el $44 \%$ pertenecen a localidades $<10.000$ habitantes. Por ello, resulta arriesgado concluir que el número de habitantes de la localidad extremeña donde se hallan los centros escolares cuyos blogs se analizan, influye directamente en su calidad, ya que solo algo más de la mitad de los blogs que superan la media se hallan en poblaciones de $>10.000$ habitantes $y$, además, blogs pertenecientes a centros de localidades muy pequeñas, que organizativamente son más complejos por la falta de personal y medios, han obtenido calificaciones muy altas, lo que supone un valor añadido para ellos.

\section{AGRADECIMIENTOS}

Este trabajo ha sido financiado por la Consejería de Educación y Cultura del Gobierno de Extremadura como parte de la licencia de estudio destinada a funcionarios de carrera de los cuerpos docentes y de los cuerpos de inspectores de educación e inspectores al servicio de la administración educativa, para el curso 2012/2013. 


\section{NOTAS}

(1) La Red de Bibliotecas Escolares de Extremadura (REBEX) ha incentivado notablemente el uso del blog en las bibliotecas escolares de Extremadura.

\section{BIBLIOGRAFÍA}

Al-Duwairi, K.; Faba-Pérez, C.; Vargas-Quesada, B. (2010). Indicadores Webmétricos de carácter Formal para Evaluar el Posicionamiento de las Universidades: el caso de los Países Árabes. Investigación Bibliotecológica: archivonomía, bibliotecología e información, vol. 24 (52), 145-171.

Ayuso García, M. D.; Martínez Navarro, V. (2006a). Evaluación de calidad de fuentes y recursos digitales: Guía de buenas prácticas. Anales de Documentación, vol. 9, 17-42.

Ayuso García, M. D.; Martínez Navarro, V. (2006b). Metodología de evaluación de recursos en bibliotecas digitales. Parámetros e indicadores de calidad. Ciencias de la Información, vol. 37 (1), 25-44.

Balslev, J.; Winther, J. (2004). Weblogs. BarceIona: Know Ware E.U.R.L.

Blasco Olivares, A.; Durban Roca, G. (2012). La competencia informacional en la enseñanza obligatoria a partir de la articulación de un modelo específico. Revista Española de Documentación Científica, vol. 35, 100-135. http:// dx.doi.org/10.3989/redc.2012.mono.979

Calderón Rehecho, A. (2006). La evaluación de páginas web. Disponible en: http://observatorio.cnice. $\mathrm{mec}$.es/modules. $\mathrm{php}$ ?op = modload\& name $=$ News \&file $=$ article $\&$ sid $=334 \quad$ [Consulta: 27/06/2013].

Castells, M. (2009). Comunicación y poder. Madrid: Alianza.

Clyde, L. A. (2004). School library Web sites: 1996-2002. Electronic Library, vol. 22 (2), 158-167. http://dx.doi. org/10.1108/02640470410533425

Consejo de Cooperación Bibliotecaria. Grupo de Trabajo de Bases Tecnológicas para la Gestión y Cooperación Bibliotecaria (2007). Recomendaciones sobre los servicios que las Bibliotecas Públicas pueden ofrecer a través de internet. Disponible en: http://travesia.mcu.es/ portalnb/jspui/handle/10421/395 [Consulta: 12/07/2013].

Directrices de la IFLA/UNESCO para la biblioteca escolar (2002). Disponible en: http://www. ifla.org/files/assets/school-libraries-resourcecenters/publications/school-library-guidelines/ school-library-guidelines-es.pdf [Consulta: 23/07/2013].
Faba-Pérez, C.; Sanz-Caballero, I. (2014). Design and Implementation of a Weighted Features Model for the Evaluation of Archival Websites: the Case of Spain. The Electronic Library, vol. 32 (2). http://dx.doi.org/10.1108/EL-072012-0094

Faba-Pérez, C.; Zapico-Alonso, F.; Guerrero-Bote, V.P.; Moya-Anegón, F. (2005). Comparative Analysis of Webometric Measurements in Thematic Environments. Journal of the American Society for Information Science and Technology (JASIST), vol. 56 (8), 779-785. http://dx.doi.org/10.1002/asi.20161

Farkas, M. G. (2007). Social software in libraries: building collaboration, communication, and community online. Medford, N.J.: Information Today.

García de León, A.; Garrido Díaz, A. (2002). Los sitios web como estructuras de información: un primer abordaje en los criterios de calidad. Biblios, vol. 3 (12), 1-17. Disponible en: http:// www. redalyc.org/articulo.oa?id $=16112303$ [Consulta: 16/09/2013].

González-Mateos, I.; Faba-Pérez, C. (2014). Modelos para evaluar la situación de las bibliotecas escolares y la calidad de sus sitios web. Investigación Bibliotecológica: archivonomía, bibliotecología e información, (en prensa), vol. 63.

Juárez Urquijo, F. (2008). Tecnología, innovación y web social: el valor de la dimensión en la biblioteca pública. El caso de la biblioteca de Muskiz. El Profesional de la Información. vol. 17 (2), 135-143. http://dx.doi.org/10.3145/ epi.2008.mar.02

Ley 4/2011, de 7 de marzo, de Educación de Extremadura. (DOE número 47 de 9 de marzo de 2011). Disponible en: http://doe.juntaex.es/ pdfs/doe/2011/470o/11010004.pdf [Consulta: 10/07/2013]

Ley Orgánica 2/2006, de 3 de mayo, de Educación (BOE número 106 de 4 de mayo de 2006). Disponible en: http://www.boe.es/buscar/doc.php?id=BOE-A-2006-7899 [Consulta: 02/07/2013].

Ley Orgánica 8/2013, de 9 de diciembre, para la Mejora de la Calidad Educativa (BOE número 10 de diciembre de 2013). Disponible en: http:// www.boe.es/boe/dias/2013/12/10/pdfs/BOEA-2013-12886.pdf [Consulta: 02/07/2013].

Luque Jaime, J.M. (2011). Aproximación al conocimiento de los blogs de bibliotecas escolares. Libro Abierto, Disponible en: http:// www.juntadeandalucia.es/educacion/webportal/web/portal-libro-abierto/detalle/-/ contenidos/detalle/blogs-de-bibliotecas-escolares-de-malaga-y-provincia [Consulta: 28/06/2013]. 
Luque, J. M. (2007). Servicios y programas de la biblioteca escolar en las páginas web de los centros educativos. Selección de recursos digitales y virtuales de apoyo al currículo. En: J. García Guerrero (dir.). La articulación de los recursos en el funcionamiento de la biblioteca escolar. Madrid: Ministerio de Educación y Ciencia.

Manifiesto de la IFLA/UNESCO sobre internet (2006). Disponible en: http://archive.ifla.org/ faife/policy/iflastat/Internet-ManifestoGuidelines-es.pdf [Consulta: 18/07/2013].

Margaix Arnal, D. (2008). Informe APEI sobre la web social. Disponible en: http://eprints.rclis. org/12506/1/informeapeiwebsocial.pdf [Consulta: $26 / 07 / 2013$ ].

Marzal, M. A.; Parra, P.; Colmenero, M. J. (2011). La medición de impacto y evaluación de programas de alfabetización en informatización para bibliotecas escolares. Revista Española de Documentación Científica, vol. 34 (2), 190-211. http://dx.doi.org/10.3989/redc.2011.2.780

Moreno Mulas, M. A. (2006). Bibliotecas blogueras: construyendo espacios de diálogo, creación y aprendizaje. III Congreso Nacional de Bibliotecas Públicas, p. 453-460. Madrid: Subdirección General de Información y Publicación.

Noguera Vivo, J. M. (2004). Una mirada atrás: rasgos y reflexiones para decidir qué es un weblog. II Congreso on-line del Observatorio para la Cibersociedad. Disponible en: http://www. cibersociedad.net/congres2004/grups/fitxacom publica2. php ?idioma $=$ es\&id $=344 \&$ grup $=4 \overline{3}$ [Consulta: 29/07/2013].

Noguera Vivo, J. M. (2008). Blogs y medios: las claves de una relación de interés mutuo. Disponible en: http://www.medellindigital.gov.co/Mediateca/repositorio\%20de\%20recursos/NogueraVivo_BlogsyMedios.pdf [Consulta: 29/09/2013].
Orden de 25 de abril de 2007 por la que se promueve la "Red de Bibliotecas Escolares de Extremadura" y se regula la incorporación a la misma de los centros educativos públicos de enseñanza no universitaria de Extremadura. (DOE número 52 de 8 de mayo de 2007). Disponible en: http://doe.juntaex.es/pdfs/ doe/2007/520o/07050202.pdf [Consulta: $10 / 07 / 2013]$

Orden de 5 de junio de 2012 por la que se modifica la Orden de 25 de abril de 2007, por la que se promueve la Red de Bibliotecas Escolares de Extremadura y se regula la incorporación a la misma de los centros educativos públicos de enseñanza no universitaria. (DOE número 115 de 15 de junio de 2012). Disponible en: http://doe. juntaex.es/pdfs/doe/2012/1150o/12050121. pdf [Consulta: 11/07/2013].

Orihuela, J. L. (2003). Entrevista a José Luis Orihuela. Disponible en: http://www.librodenotas.com/almacen/Archivos/003805.html [Consulta: 23/07/2013].

Plan Marco de Apoyo y Fomento de las Bibliotecas Escolares de Extremadura (2006). Mérida: Consejería de Educación.

Real Academia Española. (2005). Diccionario Panhispánico de Dudas (1 $1^{a}$ ed.). Madrid: Santillana.

Robert Barrera, C.; Núñez Amaro, S.; Motola Pedroso, D. (2006). Evaluación de sitios web en internet: propuestas para la evaluación de sitios web de bibliotecas públicas y de salud. Acimed, 14(4). Disponible en: http://bvs.sld.cu/revistas/aci/vol14_4_06/ aci04406.htm [Consulta: 30/08/2013].

Rodríguez Palchevich, D. R. (2010). Blogs de bibliotecas escolares argentinas (un estudio_exploratorio). (2010). Tesina de Licenciatura, Universidad Nacional de Mar del Plata. Argentina. Disponible en: http://eprints.rclis.org/15135/ [Consulta: 03/07/2013]. 
ANEXO I

Modelo ponderado de características de blogs de bibliotecas escolares

\begin{tabular}{|c|c|c|c|c|c|}
\hline Código & Característica & Peso & \multicolumn{3}{|c|}{ Grado de Cumplimiento } \\
\hline & & & 0 & 0,5 & 1 \\
\hline \multicolumn{6}{|c|}{ INFORMACIÓN GENERAL } \\
\hline C1 & URL del blog & 2,5 & $\begin{array}{l}\text { No se reconoce que } \\
\text { pertenece a la biblioteca } \\
\text { escolar del centro. }\end{array}$ & $\begin{array}{l}\text { La URL elegida no es clara } \\
\text { y se presta a confusión. }\end{array}$ & $\begin{array}{l}\text { Se reconoce con } \\
\text { claridad que pertenece } \\
\text { a la biblioteca escolar } \\
\text { del centro y es fácil de } \\
\text { recordar. }\end{array}$ \\
\hline $\mathbf{C 2}$ & $\begin{array}{l}\text { Definición de los } \\
\text { objetivos del blog }\end{array}$ & 2,5 & $\begin{array}{l}\text { No aparece información } \\
\text { sobre los objetivos del } \\
\text { blog de la biblioteca } \\
\text { escolar. }\end{array}$ & $\begin{array}{l}\text { Aparece de forma somera } \\
\text { alguna referencia a los } \\
\text { objetivos del blog de la } \\
\text { biblioteca escolar. }\end{array}$ & $\begin{array}{l}\text { Están claramente } \\
\text { definidos los objetivos } \\
\text { del blog de la biblioteca } \\
\text { escolar. }\end{array}$ \\
\hline C3 & $\begin{array}{l}\text { Identificación } \\
\text { del organismo } \\
\text { responsable } \\
\text { del blog }\end{array}$ & 2,5 & $\begin{array}{l}\text { No aparece ninguna } \\
\text { referencia sobre } \\
\text { la responsabilidad } \\
\text { intelectual del blog, } \\
\text { ni del organismo } \\
\text { responsable de su } \\
\text { publicación, ni del } \\
\text { centro al que está } \\
\text { vinculado. }\end{array}$ & $\begin{array}{l}\text { Aparece alguna referencia } \\
\text { sobre la responsabilidad } \\
\text { intelectual del blog, del } \\
\text { organismo responsable } \\
\text { de su publicación o } \\
\text { del centro al que está } \\
\text { vinculado. }\end{array}$ & $\begin{array}{l}\text { Aparece definida } \\
\text { la sede del centro } \\
\text { responsable intelectual } \\
\text { del blog. }\end{array}$ \\
\hline C4 & $\begin{array}{l}\text { Documentos } \\
\text { organizativos } \\
\text { de la biblioteca } \\
\text { escolar. } \\
\text { (Proyectos, } \\
\text { memorias...) }\end{array}$ & 2,1 & $\begin{array}{l}\text { No se proporciona } \\
\text { acceso a documentos } \\
\text { organizativos, de } \\
\text { gestión, proyectos, } \\
\text { planes de actuación } \\
\text { relativos a la biblioteca } \\
\text { escolar. }\end{array}$ & $\begin{array}{l}\text { Se proporciona un acceso } \\
\text { limitado y no actualizado } \\
\text { de documentos } \\
\text { organizativos, de gestión, } \\
\text { proyectos, planes de } \\
\text { actuación relativos a la } \\
\text { biblioteca escolar. }\end{array}$ & $\begin{array}{l}\text { Se proporciona } \\
\text { un acceso amplio } \\
\text { y actualizado } \\
\text { a documentos } \\
\text { organizativos, de } \\
\text { gestión, proyectos, } \\
\text { planes de actuación } \\
\text { relativos a la biblioteca } \\
\text { escolar. }\end{array}$ \\
\hline C5 & $\begin{array}{l}\text { Autoría. Personas } \\
\text { encargadas de su } \\
\text { mantenimiento. } \\
\text { (Administradores) }\end{array}$ & 2,6 & $\begin{array}{l}\text { No están identificados } \\
\text { los administradores } \\
\text { del blog. No existe un } \\
\text { buzón de sugerencias o } \\
\text { dirección de contacto. }\end{array}$ & $\begin{array}{l}\text { Están identificados los } \\
\text { administradores del } \\
\text { blog, pero no existe un } \\
\text { buzón de sugerencias o } \\
\text { dirección de contacto. No } \\
\text { están identificados los } \\
\text { administradores del blog, } \\
\text { pero existe buzón de } \\
\text { sugerencias o dirección } \\
\text { de contacto. }\end{array}$ & $\begin{array}{l}\text { Están correctamente } \\
\text { identificados los } \\
\text { administradores del } \\
\text { blog. Y existe un } \\
\text { buzón de sugerencias o } \\
\text { dirección de contacto. }\end{array}$ \\
\hline C6 & $\begin{array}{l}\text { Imágenes de la } \\
\text { biblioteca escolar. } \\
\text { Visita virtual }\end{array}$ & 2,3 & $\begin{array}{l}\text { No ofrece imágenes de } \\
\text { la biblioteca escolar. }\end{array}$ & $\begin{array}{l}\text { Ofrece imágenes de la } \\
\text { biblioteca escolar. El } \\
\text { acceso no es claro o las } \\
\text { imágenes son antiguas, } \\
\text { de baja calidad o no dan } \\
\text { una buena imagen de la } \\
\text { biblioteca. }\end{array}$ & $\begin{array}{l}\text { Hay un acceso claro } \\
\text { a las imágenes de } \\
\text { la biblioteca escolar. } \\
\text { Las imágenes están } \\
\text { actualizadas, de alta } \\
\text { calidad y ofrecen una } \\
\text { buena imagen de la } \\
\text { biblioteca. }\end{array}$ \\
\hline C7 & $\begin{array}{l}\text { Identificación } \\
\text { básica de las } \\
\text { entradas }\end{array}$ & 2,4 & $\begin{array}{l}\text { No aparece en las } \\
\text { entradas publicadas ni } \\
\text { el autor ni la fecha de } \\
\text { creación. }\end{array}$ & $\begin{array}{l}\text { Aparece en las entradas } \\
\text { publicadas sólo el autor o } \\
\text { la fecha de creación. }\end{array}$ & $\begin{array}{l}\text { Aparece en las } \\
\text { entradas publicadas } \\
\text { el autor y la fecha de } \\
\text { creación. }\end{array}$ \\
\hline C8 & $\begin{array}{l}\text { Títulos de las } \\
\text { entradas }\end{array}$ & 2,8 & No se utilizan títulos. & $\begin{array}{l}\text { Se utilizan títulos pero } \\
\text { son poco descriptivos. }\end{array}$ & $\begin{array}{l}\text { Los títulos describen } \\
\text { adecuadamente el } \\
\text { contenido. }\end{array}$ \\
\hline
\end{tabular}




\begin{tabular}{|c|c|c|c|c|c|}
\hline Código & Característica & Peso & \multicolumn{3}{|c|}{ Grado de Cumplimiento } \\
\hline & & & 0 & 0,5 & 1 \\
\hline C9 & $\begin{array}{l}\text { Contador de } \\
\text { visitas }\end{array}$ & 1,3 & No dispone. & $\begin{array}{l}\text { Dispone de contador pero } \\
\text { no se actualiza de forma } \\
\text { correcta. }\end{array}$ & $\begin{array}{l}\text { Dispone de contador } \\
\text { actualizado. }\end{array}$ \\
\hline C10 & $\begin{array}{l}\text { Herramientas } \\
\text { sociales. } \\
\text { Pinterest, } \\
\text { Facebook, } \\
\text { Twitter, Youtube }\end{array}$ & 1,5 & No dispone de ninguna. & $\begin{array}{l}\text { Dispone de, al menos, } \\
\text { una de ellas. }\end{array}$ & $\begin{array}{l}\text { Dispone de más de una } \\
\text { de ellas. }\end{array}$ \\
\hline C11 & $\begin{array}{l}\text { Suscripción por } \\
\text { email y RSS }\end{array}$ & 1,9 & $\begin{array}{l}\text { No permite la } \\
\text { suscripción. }\end{array}$ & $\begin{array}{l}\text { Permite la suscripción } \\
\text { por, al menos, uno de los } \\
\text { medios. }\end{array}$ & $\begin{array}{l}\text { Permite la suscripción } \\
\text { por ambos medios. }\end{array}$ \\
\hline \multicolumn{6}{|c|}{ CONTENIDOS } \\
\hline C12 & Derechos de autor & 2,7 & $\begin{array}{l}\text { No se incluyen las } \\
\text { fuentes cuando se cita. }\end{array}$ & $\begin{array}{l}\text { Se citan las fuentes pero } \\
\text { se utilizan imágenes sin el } \\
\text { debido permiso. }\end{array}$ & $\begin{array}{l}\text { Todos los recursos } \\
\text { utilizados están } \\
\text { correctamente } \\
\text { nombrados y se } \\
\text { indica la fuente de los } \\
\text { mismos. }\end{array}$ \\
\hline C13 & Navegabilidad & 2,7 & $\begin{array}{l}\text { No existen diferentes } \\
\text { secciones. }\end{array}$ & $\begin{array}{l}\text { Se ve que existen varias } \\
\text { secciones pero no se } \\
\text { ofrecen enlaces directos } \\
\text { a ellas. }\end{array}$ & $\begin{array}{l}\text { Dispone de opciones } \\
\text { de navegación claras } \\
\text { (mapa web, barra de } \\
\text { navegación, índices). }\end{array}$ \\
\hline C14 & $\begin{array}{l}\text { Herramienta } \\
\text { de navegación } \\
\text { interna }\end{array}$ & 2,2 & $\begin{array}{l}\text { No dispone de } \\
\text { herramientas de } \\
\text { búsqueda. }\end{array}$ & $\begin{array}{l}\text { Dispone de acceso a la } \\
\text { información mediante } \\
\text { la búsqueda simple por } \\
\text { palabras. }\end{array}$ & $\begin{array}{l}\text { Dispone de } \\
\text { herramientas de } \\
\text { búsqueda. Permite } \\
\text { el acceso a buscador } \\
\text { interno o a búsqueda } \\
\text { avanzada. }\end{array}$ \\
\hline C15 & $\begin{array}{l}\text { Nubes de } \\
\text { Etiquetas, Tag } \\
\text { Cloud }\end{array}$ & 1,9 & $\begin{array}{l}\text { No dispone el blog del } \\
\text { servicio al usuario de } \\
\text { nubes de etiquetas o } \\
\text { tag cloud. }\end{array}$ & $\begin{array}{l}\text { Dispone el blog del } \\
\text { servicio al usuario de } \\
\text { nubes de etiquetas o } \\
\text { tag cloud, pero no se } \\
\text { presenta de manera útil y } \\
\text { funcional para el usuario. }\end{array}$ & $\begin{array}{l}\text { Dispone el blog del } \\
\text { servicio al usuario de } \\
\text { nubes de etiquetas o } \\
\text { tag cloud, y está claro } \\
\text { y funcional para el } \\
\text { usuario. }\end{array}$ \\
\hline C16 & $\begin{array}{l}\text { Traducción. } \\
\text { Adaptación a la } \\
\text { lengua del usuario }\end{array}$ & 1,7 & $\begin{array}{l}\text { No existe versión de } \\
\text { la información en otro } \\
\text { idioma. }\end{array}$ & $\begin{array}{l}\text { Existe una versión de } \\
\text { la información en otro } \\
\text { idioma. }\end{array}$ & $\begin{array}{l}\text { Permite acceder a } \\
\text { una versión de la } \\
\text { información en otros } \\
\text { idiomas. }\end{array}$ \\
\hline C17 & $\begin{array}{l}\text { Actualización. } \\
\text { Frecuencia de las } \\
\text { entradas }\end{array}$ & 2,7 & $\begin{array}{l}\text { Sin entradas en } \\
\text { algún mes del último } \\
\text { trimestre escolar. }\end{array}$ & $\begin{array}{l}\text { Al menos una entrada } \\
\text { al mes en el último } \\
\text { trimestre escolar. }\end{array}$ & $\begin{array}{l}\text { Más de una entrada } \\
\text { al mes en el último } \\
\text { trimestre escolar. }\end{array}$ \\
\hline \multicolumn{6}{|c|}{ ENLACES } \\
\hline C18 & $\begin{array}{l}\text { Enlaces con } \\
\text { otras bibliotecas } \\
\text { escolares }\end{array}$ & 2,2 & $\begin{array}{l}\text { No existen enlaces } \\
\text { a otras bibliotecas } \\
\text { escolares. }\end{array}$ & $\begin{array}{l}\text { Existen enlaces a otras } \\
\text { bibliotecas escolares, } \\
\text { pero en número reducido } \\
\text { (menos de } 3 \text { ). }\end{array}$ & $\begin{array}{l}\text { Existen numerosos } \\
\text { enlaces a otras } \\
\text { bibliotecas escolares } \\
\text { (más de } 3 \text { ). }\end{array}$ \\
\hline C19 & $\begin{array}{l}\text { Enlaces a } \\
\text { bibliotecas } \\
\text { públicas }\end{array}$ & 2 & $\begin{array}{l}\text { No se proporcionan } \\
\text { enlaces. }\end{array}$ & $\begin{array}{l}\text { Se proporciona enlace } \\
\text { solo a una biblioteca } \\
\text { pública (de la localidad } \\
\text { o no). }\end{array}$ & $\begin{array}{l}\text { Se proporcionan varios } \\
\text { enlaces a bibliotecas } \\
\text { públicas de la localidad } \\
\text { u otras bibliotecas } \\
\text { públicas. }\end{array}$ \\
\hline C20 & $\begin{array}{l}\text { Enlaces a } \\
\text { recursos } \\
\text { educativos } \\
\text { relacionados con } \\
\text { el fomento de la } \\
\text { lectura }\end{array}$ & 2,6 & $\begin{array}{l}\text { El blog no proporciona } \\
\text { enlaces a recursos } \\
\text { educativos relacionados } \\
\text { con el fomento de la } \\
\text { lectura. }\end{array}$ & $\begin{array}{l}\text { El blog proporciona muy } \\
\text { pocos enlaces (menos de } \\
\text { 3) a recursos educativos } \\
\text { relacionados con el } \\
\text { fomento de la lectura }\end{array}$ & $\begin{array}{l}\text { El blog proporciona } \\
\text { un amplio abanico de } \\
\text { enlaces (más de } 3 \text { ) a } \\
\text { recursos educativos } \\
\text { relacionados con el } \\
\text { fomento de la lectura }\end{array}$ \\
\hline
\end{tabular}




\begin{tabular}{|c|c|c|c|c|c|}
\hline Código & Característica & Peso & \multicolumn{3}{|c|}{ Grado de Cumplimiento } \\
\hline & & & 0 & 0,5 & 1 \\
\hline C21 & $\begin{array}{l}\text { Enlaces a sitios de } \\
\text { interés: revistas } \\
\text { de literatura } \\
\text { infantil y juvenil, } \\
\text { enciclopedias, etc. }\end{array}$ & 2,7 & $\begin{array}{l}\text { El blog proporciona } \\
\text { pocos (menos de } 3 \text { ) } \\
\text { enlaces a revistas y } \\
\text { obras de referencia }\end{array}$ & $\begin{array}{l}\text { El blog proporciona } \\
\text { algunos (entre } 3 \text { y } 10 \text { ) } \\
\text { enlaces a revistas y obras } \\
\text { de referencia. }\end{array}$ & $\begin{array}{l}\text { El blog proporciona } \\
\text { bastantes (más de 10) } \\
\text { enlaces a revistas y } \\
\text { obras de referencia. }\end{array}$ \\
\hline $\mathrm{C} 22$ & $\begin{array}{l}\text { Acceso a } \\
\text { publicaciones } \\
\text { de carácter } \\
\text { informativo } \\
\text { elaboradas por la } \\
\text { biblioteca escolar }\end{array}$ & 2,6 & $\begin{array}{l}\text { No se tiene acceso } \\
\text { a publicaciones } \\
\text { elaboradas por la } \\
\text { biblioteca escolar }\end{array}$ & $\begin{array}{l}\text { Se tiene acceso a } \\
\text { alguna/s publicaciones } \\
\text { elaboradas por la } \\
\text { biblioteca escolar. }\end{array}$ & $\begin{array}{l}\text { Se tiene acceso a } \\
\text { todas las publicaciones } \\
\text { elaboradas por la } \\
\text { biblioteca escolar. }\end{array}$ \\
\hline C23 & $\begin{array}{l}\text { Acceso a la } \\
\text { revista escolar del } \\
\text { centro }\end{array}$ & 2,2 & $\begin{array}{l}\text { No dispone el sitito web } \\
\text { de acceso a la revista } \\
\text { escolar del centro. }\end{array}$ & $\begin{array}{l}\text { Se puede acceder a la } \\
\text { revista escolar del centro. } \\
\text { Se tiene acceso a la de } \\
\text { cursos anteriores, no a la } \\
\text { actual. }\end{array}$ & $\begin{array}{l}\text { Se tiene acceso a } \\
\text { la revista escolar } \\
\text { del centro y está } \\
\text { actualizada la } \\
\text { información. }\end{array}$ \\
\hline C24 & $\begin{array}{l}\text { Promoción de } \\
\text { materiales } \\
\text { elaborados por los } \\
\text { alumnos (escritos, } \\
\text { ilustraciones) }\end{array}$ & 2,8 & $\begin{array}{l}\text { No se promueven las } \\
\text { producciones creativas } \\
\text { de los alumnos y no } \\
\text { se facilita su difusión } \\
\text { desde el blog. No se } \\
\text { publican los trabajos. }\end{array}$ & $\begin{array}{l}\text { Se promueven las } \\
\text { producciones creativas de } \\
\text { los alumnos, facilitando } \\
\text { su difusión pero hay } \\
\text { pocos trabajos publicados } \\
\text { y/o no están actualizados }\end{array}$ & $\begin{array}{l}\text { Se promueven las } \\
\text { producciones creativas } \\
\text { de los alumnos, } \\
\text { facilitando su difusión. } \\
\text { Hay numerosos } \\
\text { trabajos publicados y } \\
\text { están actualizados. }\end{array}$ \\
\hline $\mathrm{C25}$ & $\begin{array}{l}\text { Recomendaciones } \\
\text { de lecturas } \\
\text { realizadas por } \\
\text { alumnos }\end{array}$ & 2,4 & $\begin{array}{l}\text { No existen } \\
\text { recomendaciones de } \\
\text { lectura realizadas } \\
\text { por alumnos. No se } \\
\text { promueve la realización } \\
\text { de las mismas. }\end{array}$ & $\begin{array}{l}\text { Se promueve la } \\
\text { realización de } \\
\text { recomendaciones de } \\
\text { lectura realizadas por } \\
\text { alumnos, pero o no hay } \\
\text { publicadas, no están } \\
\text { actualizadas o hay muy } \\
\text { pocas (menos de } 5 \text { ). }\end{array}$ & $\begin{array}{l}\text { Se promueven y } \\
\text { existen numerosas } \\
\text { recomendaciones de } \\
\text { lectura realizadas por } \\
\text { alumnos. }\end{array}$ \\
\hline C26 & $\begin{array}{l}\text { Fiabilidad de los } \\
\text { enlaces }\end{array}$ & 2,7 & $\begin{array}{l}\text { Ningún enlace de } \\
\text { la página principal } \\
\text { pertenece a fuentes } \\
\text { fiables. }\end{array}$ & $\begin{array}{l}\text { Existe algún enlace de } \\
\text { la página principal que } \\
\text { no pertenece a fuentes } \\
\text { fiables y relevantes. }\end{array}$ & $\begin{array}{l}\text { Todos los enlaces que } \\
\text { aparecen en la página } \\
\text { principal son de fuentes } \\
\text { confiables y relevantes. }\end{array}$ \\
\hline \multicolumn{6}{|c|}{ SERVICIOS } \\
\hline $\mathrm{C} 27$ & Préstamo & 1,7 & $\begin{array}{l}\text { No ofrece servicio de } \\
\text { préstamo on-line. }\end{array}$ & $\begin{array}{l}\text { Se puede realizar } \\
\text { solo alguna gestión } \\
\text { relacionada con el } \\
\text { préstamo de ejemplares. }\end{array}$ & $\begin{array}{l}\text { Permite el acceso } \\
\text { completo al préstamo } \\
\text { on-line. }\end{array}$ \\
\hline C28 & Catálogo & 2,5 & $\begin{array}{l}\text { No se dispone de } \\
\text { acceso on-line al } \\
\text { catálogo de la biblioteca } \\
\text { escolar. }\end{array}$ & $\begin{array}{l}\text { Se puede acceder al } \\
\text { catálogo on-line de la } \\
\text { biblioteca escolar, pero } \\
\text { no se puede realizar } \\
\text { consultas sobre el mismo. }\end{array}$ & $\begin{array}{l}\text { Se puede acceder al } \\
\text { catálogo on-line de } \\
\text { la biblioteca escolar } \\
\text { y se pueden realizar } \\
\text { consultas sobre el } \\
\text { mismo. }\end{array}$ \\
\hline C29 & $\begin{array}{l}\text { Orientación, } \\
\text { noticias, y } \\
\text { novedades } \\
\text { bibliográficas }\end{array}$ & 2,3 & $\begin{array}{l}\text { No se utiliza el } \\
\text { blog para publicar } \\
\text { orientaciones, } \\
\text { noticias y novedades } \\
\text { bibliográficas. }\end{array}$ & $\begin{array}{l}\text { Se utiliza en pocas } \\
\text { ocasiones (menos de } \\
3 \text { enlaces a editoriales, } \\
\text { páginas de novedades,...) } \\
\text { para publicar } \\
\text { orientaciones, noticias y } \\
\text { novedades bibliográficas. }\end{array}$ & $\begin{array}{l}\text { Se utiliza con } \\
\text { frecuencia (más } \\
\text { de } 3 \text { enlaces a } \\
\text { editoriales, páginas } \\
\text { de novedades,...) para } \\
\text { publicar orientaciones, } \\
\text { noticias y novedades } \\
\text { bibliográficas. }\end{array}$ \\
\hline
\end{tabular}




\begin{tabular}{|c|c|c|c|c|c|}
\hline Código & Característica & Peso & \multicolumn{3}{|c|}{ Grado de Cumplimiento } \\
\hline & & & 0 & 0,5 & 1 \\
\hline C30 & $\begin{array}{l}\text { Programas de } \\
\text { fomento de la } \\
\text { lectura }\end{array}$ & 2,7 & $\begin{array}{l}\text { No informa sobre los } \\
\text { programas de fomento } \\
\text { a la lectura que se } \\
\text { llevan a cabo en el } \\
\text { centro. }\end{array}$ & $\begin{array}{l}\text { Informa sobre algunos de } \\
\text { los programas de fomento } \\
\text { a la lectura que se llevan } \\
\text { a cabo en el centro, pero } \\
\text { no está actualizada la } \\
\text { información. }\end{array}$ & $\begin{array}{l}\text { Informa sobre los } \\
\text { programas de fomento } \\
\text { a la lectura que se } \\
\text { llevan a cabo en el } \\
\text { centro y la información } \\
\text { está actualizada. }\end{array}$ \\
\hline C31 & $\begin{array}{l}\text { Actividades y } \\
\text { actuaciones de la } \\
\text { biblioteca escolar }\end{array}$ & 2,8 & $\begin{array}{l}\text { No informa sobre } \\
\text { la promoción de } \\
\text { las actividades y } \\
\text { actuaciones que se } \\
\text { realizan en el centro. }\end{array}$ & $\begin{array}{l}\text { Aparece información } \\
\text { de promoción de las } \\
\text { actividades y actuaciones } \\
\text { que se realizan en } \\
\text { el centro, pero la } \\
\text { información no está } \\
\text { actualizada. }\end{array}$ & $\begin{array}{l}\text { Proporciona } \\
\text { información de } \\
\text { promoción sobre } \\
\text { las actividades y } \\
\text { actuaciones que se } \\
\text { realizan en el centro } \\
\text { y la información está } \\
\text { actualizada. }\end{array}$ \\
\hline C32 & Club de lectura & 2,4 & No hay en el centro. & $\begin{array}{l}\text { Hay, pero la información } \\
\text { que se proporciona es } \\
\text { muy escasa. }\end{array}$ & $\begin{array}{l}\text { Se informa de } \\
\text { sus actividades, } \\
\text { programación. Si } \\
\text { dispone de sitio web se } \\
\text { proporciona enlace al } \\
\text { mismo. }\end{array}$ \\
\hline
\end{tabular}

\section{ANEXO II}

\section{Blogs de la Comunidad de Extremadura. Puntuación total}

\begin{tabular}{|c|c|c|c|c|c|}
\hline \multicolumn{3}{|c|}{$\begin{array}{l}\text { Puntuación y } \\
\text { Nombre del blog }\end{array}$} & URL del blog & Centro & $\begin{array}{l}\text { Localidad y } \\
\text { Provincia }\end{array}$ \\
\hline 1 & 61,70 & $\begin{array}{l}\text { Bibliotecado- } \\
\text { nalvaro }\end{array}$ & $\begin{array}{l}\text { http://bibliotecadonalvaro.blogspot. } \\
\text { com.es/ }\end{array}$ & CEIP Pío XII & Don Álvaro (BA) \\
\hline 2 & 59,60 & $\begin{array}{l}\text { El baúl de } \\
\text { Lady Book }\end{array}$ & $\begin{array}{l}\text { http://elbauldeladybook.blogspot.com. } \\
\text { es/ }\end{array}$ & CEIP Alba Plata & Cáceres (CC) \\
\hline 3 & 56,15 & $\begin{array}{l}\text { El bosque de } \\
\text { los libros }\end{array}$ & $\begin{array}{l}\text { http://elbosquedeloslibros.blogspot. } \\
\text { com.es/ }\end{array}$ & CRA Traslasierra & $\begin{array}{l}\text { Castañar de Ibor, Rebo- } \\
\text { llar, Cabezabellosa (CC) }\end{array}$ \\
\hline 4 & 55,70 & $\begin{array}{l}\text { Biblioteca } \\
\text { Calatrava }\end{array}$ & $\begin{array}{l}\text { http://bibliotecajmcalatrava.blogspot. } \\
\text { com.es/ }\end{array}$ & $\begin{array}{l}\text { CEIP José María } \\
\text { de Calatrava }\end{array}$ & Mérida (BA) \\
\hline 5 & 54,75 & $\begin{array}{l}\text { Biblioteca del } \\
\text { CEIP "Fco. } \\
\text { Ortiz López" }\end{array}$ & $\begin{array}{l}\text { http://olivenzabibliotecacolegiopublico. } \\
\text { blogspot.com.es/ }\end{array}$ & $\begin{array}{l}\text { CEIP Francisco Ortiz } \\
\text { López }\end{array}$ & Olivenza (BA) \\
\hline 6 & 53,30 & $\begin{array}{l}\text { Escritos a } \\
\text { Palíndromo }\end{array}$ & $\begin{array}{l}\text { http://bibliotecaceipalfonsoviii.blogs- } \\
\text { pot.com.es/ }\end{array}$ & CEIP Alfonso VIII & Plasencia (CC) \\
\hline 7 & 52,00 & $\begin{array}{l}\text { The Boo- } \\
\text { kWorm } \\
\text { Library }\end{array}$ & $\begin{array}{l}\text { http://thebookwormlibrary.blogspot. } \\
\text { com.es/ }\end{array}$ & CEIP Castra Caecelia & Cáceres (CC) \\
\hline 8 & 51,15 & $\begin{array}{l}\text { Biblioteca CP } \\
\text { Arias Montano }\end{array}$ & $\begin{array}{l}\text { http://bibliotecaariasmontano.blogs- } \\
\text { pot.com.es/ }\end{array}$ & CEIP Arias Montano & Badajoz (BA) \\
\hline 9 & 49,40 & Biblioabrazo & http://biblioabrazo.wordpress.com/ & CEIP Gabriel y Galán & Cáceres (CC) \\
\hline 10 & 46,10 & Bibliovaldés & http://bibliovaldes.blogspot.com.es/ & $\begin{array}{l}\text { CEIP } \\
\text { Francisco Valdés }\end{array}$ & Don Benito (BA) \\
\hline
\end{tabular}




\begin{tabular}{|c|c|c|c|c|c|}
\hline \multicolumn{3}{|c|}{$\begin{array}{l}\text { Puntuación y } \\
\text { Nombre del blog }\end{array}$} & URL del blog & Centro & $\begin{array}{l}\text { Localidad y } \\
\text { Provincia }\end{array}$ \\
\hline 11 & 44,05 & $\begin{array}{l}\text { Botijos de } \\
\text { biblioteca }\end{array}$ & $\begin{array}{l}\text { http://www.bibliocpsalvatierra.blogs- } \\
\text { pot.com.es/ }\end{array}$ & $\begin{array}{l}\text { CEIP } \\
\text { Stmo Cristo de las Mise- } \\
\text { ricordias }\end{array}$ & $\begin{array}{l}\text { Salvatierra de los Barros } \\
\text { (BA) }\end{array}$ \\
\hline 12 & 43,60 & Biblio@rgeme & http://biblioargeme.blogspot.com.es/ & $\begin{array}{l}\text { CEIP } \\
\text { Virgen de Argeme }\end{array}$ & Coria (CC) \\
\hline 13 & 43,35 & $\begin{array}{l}\text { El refugio del } \\
\text { lector }\end{array}$ & $\begin{array}{l}\text { http://ceipgabrielygalan.blogspot.com. } \\
\text { es/ }\end{array}$ & CEIP Gabriel y Galán & Cáceres (CC) \\
\hline 14 & 43,30 & $\begin{array}{l}\text { Biblioteca } \\
\text { CEIP Suárez } \\
\text { Somontes }\end{array}$ & http://somonti.blogspot.com.es/ & CEIP Suárez Somontes & Mérida (BA) \\
\hline 15 & 43,15 & Octaviolandia & http://octaviolandia.wordpress.com/ & CEIP La Acequia & Puebla de Argeme (CC) \\
\hline 16 & 41,30 & $\begin{array}{l}\text { Biblioteca } \\
\text { Miralvalle }\end{array}$ & $\begin{array}{l}\text { http://bibliotecamiralvalle.blogspot. } \\
\text { com.es/ }\end{array}$ & CEIP Miralvalle & Plasencia (CC) \\
\hline 17 & 40,30 & $\begin{array}{l}\text { Una cesta lle- } \\
\text { na de libros }\end{array}$ & http://belosarcos.blogspot.com.es/ & CEIP Los Arcos & $\begin{array}{l}\text { Malpartida de Cáceres } \\
\text { (CC) }\end{array}$ \\
\hline 18 & 39,55 & $\begin{array}{l}\text { El gusanillo } \\
\text { de la lectura }\end{array}$ & $\begin{array}{l}\text { http://bibliotecacpluisdemorales.blogs- } \\
\text { pot.com.es/ }\end{array}$ & CEIP Luis de Morales & Badajoz (BA) \\
\hline 19 & 39,55 & $\begin{array}{l}\text { Biblioteca } \\
\text { escolar "San } \\
\text { José" }\end{array}$ & $\begin{array}{l}\text { http://www.bibliotecacolegiotalavera. } \\
\text { es/ }\end{array}$ & CEIP San José & Talavera la Real (BA) \\
\hline 20 & 39,00 & $\begin{array}{l}\text { CEIP "Ntra } \\
\text { Sra de la } \\
\text { Caridad" } \\
\text { Biblioteca }\end{array}$ & http://bibliocentro.wordpress.com/ & CEIP La Caridad & La Garrovilla (BA) \\
\hline 21 & 38,75 & $\begin{array}{l}\text { Biblioteca } \\
\text { José Luis Díez } \\
\text { Calurano }\end{array}$ & $\begin{array}{l}\text { http://bibliotecajoseluisdiezcalurano. } \\
\text { blogspot.com.es/ }\end{array}$ & CEIP Santa Lucía & $\begin{array}{l}\text { Puebla de Sancho Pérez } \\
\text { (BA) }\end{array}$ \\
\hline 22 & 38,70 & $\begin{array}{l}\text { Bibliocole - } \\
\text { Almanzor }\end{array}$ & $\begin{array}{l}\text { http://rojarojaamapola.blogspot.com. } \\
\text { es/ }\end{array}$ & CEIP Almanzor & $\begin{array}{l}\text { Navalmoral de la Mata } \\
\text { (CC) }\end{array}$ \\
\hline 23 & 38,25 & $\begin{array}{l}\text { El Biblioa- } \\
\text { brazo }\end{array}$ & http://www.biblioabrazo.com/ & $\begin{array}{l}\text { CEIP } \\
\text { Gabriel y Galán }\end{array}$ & Cáceres (CC) \\
\hline 24 & 36,65 & $\begin{array}{l}\text { Biblioteca } \\
\text { escolar CEIP } \\
\text { Cruz del Río }\end{array}$ & http://cpcruzdelrio.blogspot.com.es/ & CEIP Cruz del Río & $\begin{array}{l}\text { Villanueva de la Serena } \\
\text { (BA) }\end{array}$ \\
\hline 25 & 35,35 & $\begin{array}{l}\text { Nuestra Bi- } \\
\text { blioteca }\end{array}$ & $\begin{array}{l}\text { http://ceipntrasrdelaluz.blogspot.com. } \\
\text { es/ }\end{array}$ & CEIP Ntra Sra de la Luz & Arroyo de la Luz (CC) \\
\hline 26 & 34,90 & $\begin{array}{l}\text { bibliotecacep- } \\
\text { cervantes }\end{array}$ & $\begin{array}{l}\text { http://cepcervantesbiblioteca.blogspot. } \\
\text { com.es/ }\end{array}$ & CEIP Cervantes & Moraleja (CC) \\
\hline 27 & 34,90 & $\begin{array}{l}\text { CEIP Cruz Va- } \\
\text { lero. La Pera } \\
\text { Pirata. }\end{array}$ & http://ceipcruzvalero.blogspot.com.es/ & CEIP Cruz Valero & Fuente del Maestre (BA) \\
\hline 28 & 34,25 & $\begin{array}{l}\text { La biblioteca } \\
\text { del cole }\end{array}$ & $\begin{array}{l}\text { http://labibliotecadelcoleluisvives. } \\
\text { blogspot.com.es/ }\end{array}$ & CEIP Luis Vives & Badajoz (BA) \\
\hline 29 & 34,00 & $\begin{array}{l}\text { Investigación } \\
\text { en marcha ... }\end{array}$ & $\begin{array}{l}\text { http://www.investigacionenmarcha. } \\
\text { blogspot.com.es/ }\end{array}$ & CEIP Juan XXIII & Mérida (BA) \\
\hline 30 & 33,20 & $\begin{array}{l}\text { Biblioteca } \\
\text { "Sotomayor y } \\
\text { Terrazas" }\end{array}$ & $\begin{array}{l}\text { http://bibliotecasotomayoryterrazas. } \\
\text { blogspot.com.es/ }\end{array}$ & $\begin{array}{l}\text { CEIP } \\
\text { Sotomayor y Terrazas }\end{array}$ & $\begin{array}{l}\text { Jerez de los Caballeros } \\
\text { (BA) }\end{array}$ \\
\hline 31 & 32,50 & $\begin{array}{l}\text { El blog de la } \\
\text { biblioteca }\end{array}$ & $\begin{array}{l}\text { http://www.bibliotecamontellanin. } \\
\text { blogspot.com.es/ }\end{array}$ & CRA Montellano & $\begin{array}{l}\text { Berzocana, Conquista, } \\
\text { Garciaz y Herguijuela. } \\
\text { (CC) }\end{array}$ \\
\hline
\end{tabular}




\begin{tabular}{|c|c|c|c|c|c|}
\hline \multicolumn{3}{|c|}{$\begin{array}{l}\text { Puntuación y } \\
\text { Nombre del blog }\end{array}$} & \multicolumn{2}{|l|}{ URL del blog } & \multirow[b]{2}{*}{$\begin{array}{l}\text { Esparragosa de la Serena } \\
\text { y Puerto Hurraco (BA) }\end{array}$} \\
\hline 32 & 31,25 & $\begin{array}{l}\text { Leo y te } \\
\text { cuento }\end{array}$ & http://leoytelocuento.blogspot.com.es/ & $\begin{array}{l}\text { CRA } \\
\text { Esparragosa de la } \\
\text { Serena }\end{array}$ & \\
\hline 33 & 30,95 & $\begin{array}{l}\text { Biblioteca } \\
\text { escolar "El } \\
\text { Tuerín" }\end{array}$ & $\begin{array}{l}\text { http://bibliotecaescolartuerin.blogspot. } \\
\text { com.es/ }\end{array}$ & $\begin{array}{l}\text { CEIP } \\
\text { Virgen de la Soledad }\end{array}$ & Torreorgaz (CC) \\
\hline 34 & 30,55 & $\begin{array}{l}\text { Biblioescuela } \\
\text { De Gabriel }\end{array}$ & $\begin{array}{l}\text { http://bibliotecadegabriel.blogspot. } \\
\text { com.es/ }\end{array}$ & CEIP De Gabriel & Gévora (BA) \\
\hline 35 & 29,95 & Leo con Leo & $\begin{array}{l}\text { http://bibliotecaescolareiglesias.blogs- } \\
\text { pot.com.es/ }\end{array}$ & $\begin{array}{l}\text { CEIP } \\
\text { Enrique Iglesias }\end{array}$ & Badajoz (BA) \\
\hline 36 & 29,95 & $\begin{array}{l}\text { Biblioteca del } \\
\text { Colegio Ma- } \\
\text { nuel Pacheco }\end{array}$ & $\begin{array}{l}\text { http://biblioescuelapacheco.blogspot. } \\
\text { com.es/ }\end{array}$ & CEIP Manuel Pacheco & Badajoz (BA) \\
\hline 37 & 29,00 & $\begin{array}{l}\text { Candela y sus } \\
\text { bibliotecas }\end{array}$ & $\begin{array}{l}\text { http://candelaysusbibliotecas.blogspot. } \\
\text { com.es/ }\end{array}$ & $\begin{array}{l}\text { CRA } \\
\text { Riscos de Villavieja }\end{array}$ & $\begin{array}{l}\text { Casas del Castañar, } \\
\text { Barrado, Cabrero y Val- } \\
\text { deastillas (CC) }\end{array}$ \\
\hline 38 & 28,85 & $\begin{array}{l}\text { Biblioteca } \\
\text { CEIP Santísi- } \\
\text { ma Trinidad }\end{array}$ & $\begin{array}{l}\text { http://bibliotecasantisimatrinidad. } \\
\text { blogspot.com.es/ }\end{array}$ & $\begin{array}{l}\text { CEIP } \\
\text { Santísima Trinidad }\end{array}$ & Trujillanos (BA) \\
\hline 39 & 28,80 & $\begin{array}{l}\text { Biblioteca } \\
\text { "Antonio Gar- } \\
\text { cía García" }\end{array}$ & $\begin{array}{l}\text { http://bibliotecajosevirel.blogspot.com. } \\
\text { es/ }\end{array}$ & CEIP José Virel & La Albuera (BA) \\
\hline 40 & 28,20 & $\begin{array}{l}\text { El blog de } \\
\text { Cumplasa }\end{array}$ & http://cumplasablog.blogspot.com.es/ & $\begin{array}{l}\text { CRA } \\
\text { Maestro D, Victoriano } \\
\text { Mateos }\end{array}$ & $\begin{array}{l}\text { La Cumbre, Plasenzuela } \\
\text { y Sta Marta de Magasca } \\
\text { (CC) }\end{array}$ \\
\hline 41 & 28,05 & Zampaletras & $\begin{array}{l}\text { http://biblioteca-zampaletras.blogspot. } \\
\text { com.es/ }\end{array}$ & CEIP San Pedro & San Pedro de Mérida (BA) \\
\hline 42 & 27,25 & $\begin{array}{l}\text { Leer siempre } \\
\text { es un viaje } \\
\text { sorprendente }\end{array}$ & http://leeresviajar.blogspot.com.es/ & $\begin{array}{l}\text { CEIP } \\
\text { Príncipe de Asturias }\end{array}$ & Montijo (BA) \\
\hline 43 & 26,50 & $\begin{array}{l}\text { La sala de la } \\
\text { fantasía }\end{array}$ & $\begin{array}{l}\text { http://www.salafantasia2.blogspot. } \\
\text { com.es/ }\end{array}$ & $\begin{array}{l}\text { CEIP } \\
\text { Ntra Sra Antigua }\end{array}$ & Mérida (BA) \\
\hline 44 & 26,45 & $\begin{array}{l}\text { Leo, leo, } \\
\text { requeteleo }\end{array}$ & http://leoleopiornal.blogspot.com.es/ & $\begin{array}{l}\text { CEIP } \\
\text { Máximo Cruz Rebosa }\end{array}$ & Piornal (CC) \\
\hline 45 & 26,40 & $\begin{array}{l}\text { El bosque de } \\
\text { los sueños de } \\
\text { Librín }\end{array}$ & $\begin{array}{l}\text { http://bibliogregoriacollado.blogspot. } \\
\text { com.es/ }\end{array}$ & $\begin{array}{l}\text { CEIP } \\
\text { Gregoria Collado }\end{array}$ & Jaraíz de la Vera (CC) \\
\hline 46 & 26,35 & $\begin{array}{l}\text { Una lectura } \\
\text { tuya }\end{array}$ & http://cralasvilluercas.wordpress.com/ & $\begin{array}{l}\text { CRA } \\
\text { Las Villuercas }\end{array}$ & $\begin{array}{l}\text { Navezuelas, Deleitosa, } \\
\text { Robledollano y Roturas } \\
\text { (CC) }\end{array}$ \\
\hline 47 & 26,15 & $\begin{array}{l}\text { Biblioteca Feli } \\
\text { Ceballos }\end{array}$ & $\begin{array}{l}\text { http://bibliotecadehernancortes.blogs- } \\
\text { pot.com.es/ }\end{array}$ & CEIP 12 de octubre & Hernán Cortés (BA) \\
\hline 48 & 26,05 & $\begin{array}{l}\text { Biblioteca } \\
\text { CEIP San José }\end{array}$ & $\begin{array}{l}\text { http://blogbibliotecacolecalamonte. } \\
\text { blogspot.com.es/ }\end{array}$ & CEIP San Jose & Calamonte (BA) \\
\hline 49 & 25,35 & $\begin{array}{l}\text { Biblioteca } \\
\text { Santo Tomás }\end{array}$ & $\begin{array}{l}\text { http://stomasbiblioteca.blogspot.com. } \\
\text { es/ }\end{array}$ & $\begin{array}{l}\text { CEIP } \\
\text { Santo Tomás de Aquino }\end{array}$ & Badajoz (BA) \\
\hline 50 & 24,95 & $\begin{array}{l}\text { Un bosque de } \\
\text { libros }\end{array}$ & $\begin{array}{l}\text { http://cpntrasradesopetran.blogspot. } \\
\text { com.es/ }\end{array}$ & $\begin{array}{l}\text { CEIP } \\
\text { Ntra Sra de Sopetrán }\end{array}$ & Almoharín (CC) \\
\hline 51 & 24,35 & $\begin{array}{l}\text { Lemu- } \\
\text { cho iiqué } \\
\text { divertido es } \\
\text { leer!! }\end{array}$ & http://germancid1.blogspot.com.es/ & CEIP Germán Cid & Zafra (BA) \\
\hline 52 & 23,05 & $\begin{array}{l}\text { Bibliocervan- } \\
\text { tes }\end{array}$ & $\begin{array}{l}\text { http://bibliotecaescolarceipcervantes. } \\
\text { blogspot.com.es/ }\end{array}$ & CEIP Cervantes & Cáceres (CC) \\
\hline
\end{tabular}




\begin{tabular}{|c|c|c|c|c|c|}
\hline \multicolumn{3}{|c|}{$\begin{array}{l}\text { Puntuación y } \\
\text { Nombre del blog }\end{array}$} & \multicolumn{2}{|l|}{ URL del blog } & \multirow[t]{2}{*}{$\begin{array}{l}\text { Localidad y } \\
\text { Provincia }\end{array}$} \\
\hline 53 & 23,00 & $\begin{array}{l}\text { Biblioblog } \\
\text { educativo }\end{array}$ & $\begin{array}{l}\text { http://biblioblogeducativo2012.blogs- } \\
\text { pot.com.es/ }\end{array}$ & $\begin{array}{l}\text { CEIP } \\
\text { Ntra Sra de Fuentesanta }\end{array}$ & \\
\hline 54 & 22,75 & $\begin{array}{l}\text { Blogbiblioma- } \\
\text { chado }\end{array}$ & $\begin{array}{l}\text { http://blogbibliomachado.blogspot. } \\
\text { com.es/ }\end{array}$ & CEIP Antonio Machado & Almendralejo (BA) \\
\hline 55 & 22,75 & $\begin{array}{l}\text { Bibliosanpe- } \\
\text { dro }\end{array}$ & http://bibliosanpedro.blogspot.com.es/ & $\begin{array}{l}\text { CEIP } \\
\text { San Pedro de Alcántara }\end{array}$ & Badajoz (BA) \\
\hline 56 & 22,30 & $\begin{array}{l}\text { CEIP Fausto } \\
\text { Maldonado }\end{array}$ & $\begin{array}{l}\text { http://ceipfaustomaldonado.blogspot. } \\
\text { com.es/ }\end{array}$ & CEIP Fausto Maldonado & Cañamero (CC) \\
\hline 57 & 21,10 & $\begin{array}{l}\text { Biblioteca } \\
\text { CRA "Valle del } \\
\text { Alagón" }\end{array}$ & http://biblioalagon.blogspot.com.es/ & CRA Valle del Alagón & $\begin{array}{l}\text { Alagón del Río y Galisteo } \\
\text { (CC) }\end{array}$ \\
\hline 58 & 21,10 & Practiquiteka & http://practiquiteka.blogspot.com.es/ & CEIP Prácticas & Cáceres (CC) \\
\hline 59 & 20,85 & $\begin{array}{l}\text { Bibliotecalui- } \\
\text { sapina }\end{array}$ & $\begin{array}{l}\text { http://bibliotecaluisapina.blogspot. } \\
\text { com.es/ }\end{array}$ & $\begin{array}{l}\text { CEIP } \\
\text { Francisco de Parada }\end{array}$ & Medina de las Torres (BA) \\
\hline 60 & 19,80 & $\begin{array}{l}\text { Biblioteca } \\
\text { CRA Orden de } \\
\text { Santiago }\end{array}$ & $\begin{array}{l}\text { http://craordendesantiago.blogspot. } \\
\text { com.es/ }\end{array}$ & CRA Orden de Santiago & $\begin{array}{l}\text { Albalá, Montánchez, } \\
\text { Salvatierra de Santiago, } \\
\text { Torre de Santa María y } \\
\text { Zarza de Montánchez. } \\
\text { (CC) }\end{array}$ \\
\hline 61 & 19,70 & $\begin{array}{l}\text { Biblioteca } \\
\text { CEIP Antonio } \\
\text { Chavero }\end{array}$ & $\begin{array}{l}\text { http://bibliotecaescolarceipantoniocha- } \\
\text { vero.blogspot.com.es/ }\end{array}$ & CEIP Antonio Chavero & Usagre (BA) \\
\hline 62 & 19,60 & $\begin{array}{l}\text { La ratita ses- } \\
\text { mera }\end{array}$ & $\begin{array}{l}\text { http://bibliotecacptorresnaharro.blogs- } \\
\text { pot.com.es/ }\end{array}$ & CEIP Torres Naharro & $\begin{array}{l}\text { Torre de Miguel Sesmero } \\
\text { (BA) }\end{array}$ \\
\hline 63 & 19,35 & $\begin{array}{l}\text { Biblioteca del } \\
\text { CEIP Ntra Sra } \\
\text { Bótoa }\end{array}$ & http://botoa.blogspot.com.es/ & CEIP Ntra Sra de Bótoa & Badajoz (BA) \\
\hline 64 & 18,65 & $\begin{array}{l}\text { Leo con Leo- } \\
\text { nardo }\end{array}$ & http://leoconleo.blogspot.com.es/ & $\begin{array}{l}\text { CEIP } \\
\text { Ntra Sra de la Asunción }\end{array}$ & Valverde del Fresno (CC) \\
\hline 65 & 18,25 & $\begin{array}{l}\text { Biblioteca } \\
\text { CEIP San } \\
\text { Francisco } \\
\end{array}$ & $\begin{array}{l}\text { http://biblioteca-sanfrancisco.blogspot. } \\
\text { com.es/ }\end{array}$ & CEIP San Francisco & Almendralejo (BA) \\
\hline 66 & 18,05 & $\begin{array}{l}\text { El guardián de } \\
\text { las palabras }\end{array}$ & $\begin{array}{l}\text { http://bibliotequeandoejido.blogspot. } \\
\text { com.es/ }\end{array}$ & CEIP Ejido & Jaraíz de la Vera (CC) \\
\hline 67 & 17,05 & $\begin{array}{l}\text { El blog del } \\
\text { Pastor Sito }\end{array}$ & $\begin{array}{l}\text { http://elblogdelpastorsito.blogspot. } \\
\text { com.es/ }\end{array}$ & CEIP Pastor Sito & Badajoz (BA) \\
\hline 68 & 16,50 & $\begin{array}{l}\text { Biblioteca } \\
\text { Fonteña }\end{array}$ & $\begin{array}{l}\text { http://bibliotecalasanzfue.blogspot. } \\
\text { com.es/ }\end{array}$ & $\begin{array}{l}\text { CEIP San José } \\
\text { de Calasanz }\end{array}$ & Fuente del Maestre (BA) \\
\hline 69 & 16,20 & $\begin{array}{l}\text { Biblioteca } \\
\text { Aladino }\end{array}$ & http://bibliotecaaladino.blogspot.com.es/ & CEIP Tena Artigas & Castuera (BA) \\
\hline 70 & 15,95 & $\begin{array}{l}\text { Biblioteca } \\
\text { de Alía: El } \\
\text { bosque de las } \\
\text { letras }\end{array}$ & http://bibliotecaalia.blogspot.com.es/ & $\begin{array}{l}\text { CEIP } \\
\text { Licinio de la Fuente }\end{array}$ & Alía (CC) \\
\hline 71 & 14,25 & Pulpilector & http://pulpilector.blogspot.com.es/ & CEIP San José Obrero & Rincón del Obispo (CC) \\
\hline 72 & 13,10 & $\begin{array}{l}\text { Biblioteca del } \\
\text { CEIP Cerro de } \\
\text { Reyes }\end{array}$ & http://cerrodereyes.blogspot.com.es/ & CEIP Cerro de Reyes & Badajoz (BA) \\
\hline 73 & 11,80 & $\begin{array}{l}\text { CEIP Mozte- } \\
\text { zuma }\end{array}$ & http://ceipmoctezuma.blogspot.com.es/ & CEIP Moctezuma & Cáceres (CC) \\
\hline
\end{tabular}




\begin{tabular}{|c|c|c|c|c|c|}
\hline \multicolumn{3}{|c|}{$\begin{array}{l}\text { Puntuación y } \\
\text { Nombre del blog }\end{array}$} & URL del blog & Centro & $\begin{array}{l}\text { Localidad y } \\
\text { Provincia }\end{array}$ \\
\hline 74 & 11,80 & $\begin{array}{l}\text { Campamento } \\
\text { de Lectura: } \\
\text { Noche Mr. } \\
\text { Scott }\end{array}$ & http://ceiplogrosan.blogspot.com.es/ & $\begin{array}{l}\text { CEIP } \\
\text { Ntra Sra del Consuelo }\end{array}$ & Logrosán (CC) \\
\hline 75 & 8,85 & $\begin{array}{l}\text { B.E. "El Pilar": } \\
\text { Pilarteca }\end{array}$ & $\begin{array}{l}\text { http://pilarteca-bibliotecaescolar.blogs- } \\
\text { pot.com.es/ }\end{array}$ & CEIP El Pilar & Plasencia (CC) \\
\hline
\end{tabular}

